\title{
Images
}

\section{An unusual case of exertional dyspnea: Atrial myxoma on point-of-care ultrasound}

\author{
Derek J. Murray, $\mathrm{MD}^{*}{ }^{\dagger}$; Daniel J. Kim, $\mathrm{MD}^{*}$
}

A previously healthy 59-year-old female presented to the emergency department (ED) with a 1-month history of progressive shortness of breath on exertion rapidly resolving with rest. She had no chest pain nausea or diaphoresis. An exercise stress test was positive for ischemia but a follow-up sestamibi scan was normal. A subsequent computed tomography coronary angiogram was suspicious for an atrial myxoma.

In the $\mathrm{ED}$, her vital signs were within normal limits, and her physical exam was unremarkable. An electrocardiogram revealed normal sinus rhythm, and her troponin was negative. A point-of-care ultrasound demonstrated a $67-\mathrm{mm} \times 35-\mathrm{mm}$ hyperechoic lesion in the left atrium extruding into the left ventricle during atrial systole, resulting in moderate mitral regurgitation (Figures 1-3, Supplemental Videos 1-3). Both atria were dilated, and the left ventricular ejection fraction was normal. The mass was subsequently resected and diagnosed via histopathology as an atrial myxoma.

Myxomas are the most common primary benign cardiac neoplasm, with $80 \%$ arising from the left atrium. ${ }^{1}$ The main alternative consideration for this type of lesion on echocardiography is an atrial thrombus. A mobile hyperechoic lesion with a stalk arising from the interatrial septum favours myxoma. ${ }^{2}$ On physical examination, one-third of patients will have an early diastolic murmur after the second heart sound, called a "tumor plop."3 They present on a wide clinical spectrum from asymptomatic to acute heart failure and malignant arrhythmias. ${ }^{4}$ They can also present with neurologic symptoms secondary to embolization or constitutional symptoms secondary to tumour release of growth factor and cytokines. $^{5-7}$ These tumours require surgical excision due to

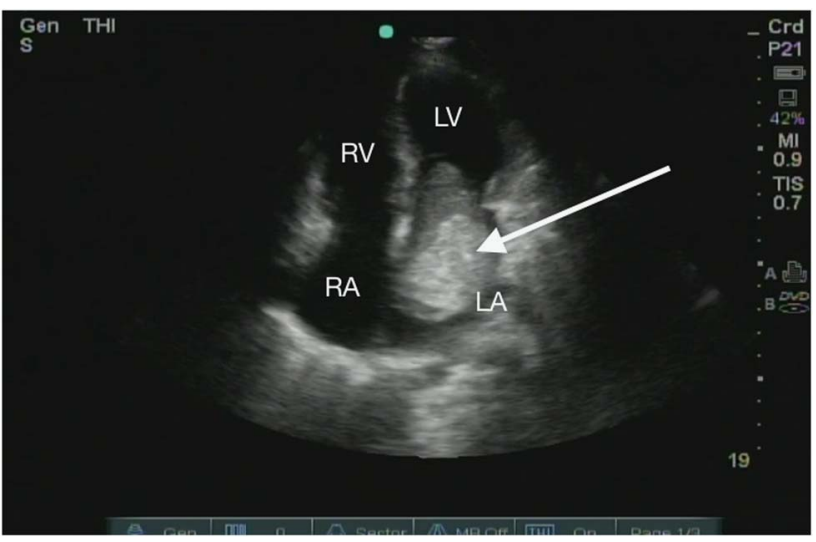

Figure 1. Apical four-chamber view of a left atrial myxoma (arrow) extruding into the left ventricle during atrial systole. $\mathrm{LA}=$ left atrium; $\mathrm{LV}=$ left ventricle; $\mathrm{RA}=$ right atrium; $\mathrm{RV}=$ right ventricle.

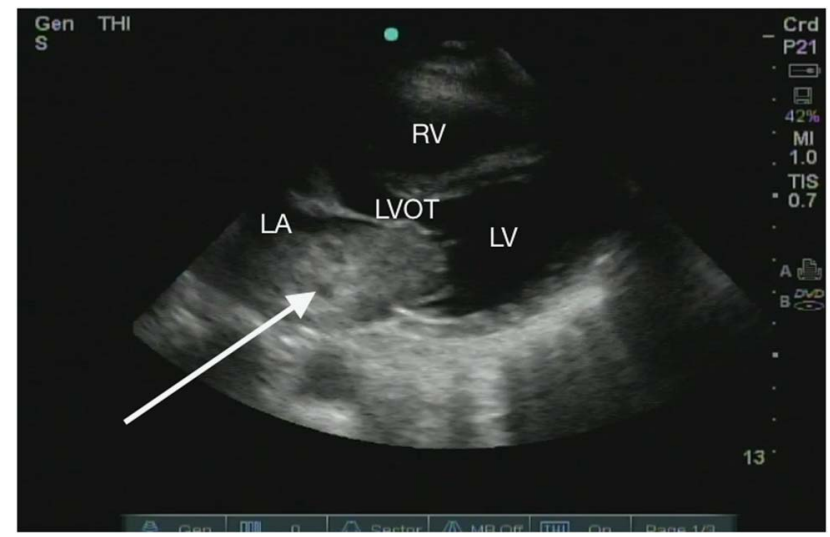

Figure 2. Parasternal long-axis view of a left atrial myxoma (arrow) extruding into the left ventricle during atrial systole. LA = left atrium; LV = left ventricle; LVOT = left ventricular outflow tract; $\mathrm{RV}=$ right ventricle.

From the *Department of Emergency Medicine, University of British Columbia, Vancouver, BC; †Department of Emergency Medicine, St. Paul's Hospital, Vancouver, BC; and the $¥$ Department of Emergency Medicine, Vancouver General Hospital, Vancouver, BC.

Correspondence to: Dr. Daniel Kim, Vancouver General Hospital, Department of Emergency Medicine, 855 12th Ave. W., Vancouver, BC V5Z 1M9; Email: dkim000@gmail.com 


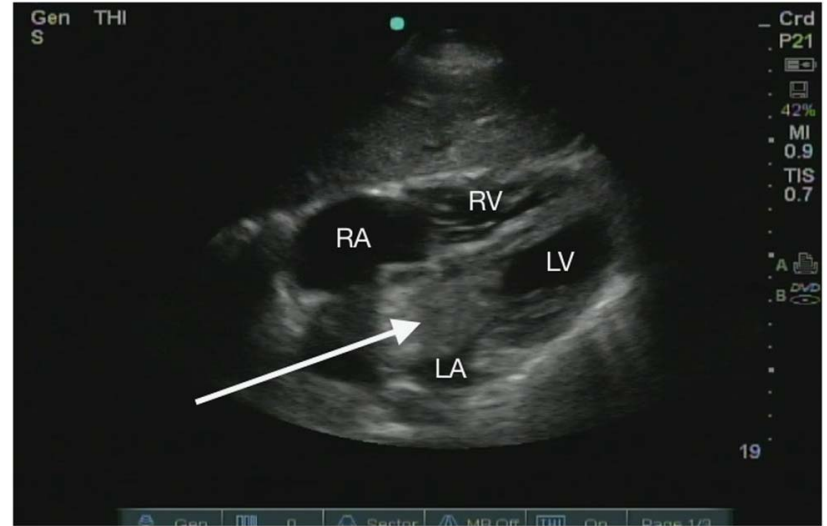

Figure 3. Subxiphoid view of a left atrial myxoma (arrow) extruding into the left ventricle during atrial systole. $\mathrm{LA}=$ left atrium; $\mathrm{LV}=$ left ventricle; $\mathrm{RA}=$ right atrium; $\mathrm{RV}=$ right ventricle

the risk of embolization and cardiac complications, including arrhythmias and sudden death. ${ }^{8-10}$

Competing interests: None declared.

Keywords: atrial myxoma, echocardiography, point of care ultrasound, emergency ultrasound

\section{SUPPLEMENTARY MATERIAL}

To view supplementary material for this article, please visit https://doi.org/10.1017/cem.2017.351

\section{REFERENCES}

1. Vander Salm TJ. Unusual primary tumors of the heart. Semin Thorac Cardiovasc Surg 2000;12:89-100.

2. Dhawan S, Tak T. Left atrial mass: thrombus mimicking myxoma. Echocardiography 2004;21:621-3.

3. Reynen K. Cardiac myxomas. N Engl f Med 1995;333:1610-7.

4. Pinede L, Duhaut P, Loire R. Clinical presentation of left atrial cardiac myxoma. A series of 112 consecutive cases. Medicine (Baltimore) 2001;80:159-72.

5. Wang Z, Chen S, Zhu M, et al. Risk prediction for emboli and recurrence of primary cardiac myxomas after resection. 7 Cardiothorac Surg 2016;11:22.

6. Sakamoto H, Sakamaki T, Kanda T, et al. Vascular endothelial growth factor is an autocrine growth factor for cardiac myxoma cells. Circ 7 2004;68:488-93.

7. Seino Y, Ikeda U, Shimada K. Increased expression of interleukin 6 mRNA in cardiac myxomas. Br Heart 7 1993;69:565-7.

8. Keeling IM, Oberwalder P, Anelli-Monti M, et al. Cardiac myxomas: 24 years of experience in 49 patients. Eur 7 Cardiothorac Surg 2002;22:971-7.

9. Selkane C, Amahzoune B, Chavanis N, et al. Changing management of cardiac myxoma based on a series of 40 cases with long-term follow-up. Ann Thorac Surg 2003;76:1935-8.

10. Cina SJ, Smialek JE, Burke AP, et al. Primary cardiac tumors causing sudden death: a review of the literature. $A m$ f Forensic Med Pathol 1996;17:271-81. 